\title{
La política del lenguaje y el abordaje de la diversidad cultural en el ámbito educativo mexicano
}

\section{Language policy and approaches to cultural diversity on the mexican education system}

\author{
iD Fernando Lara-Piña ${ }^{1}$ \& iD Emma Hilda Ortega-Rodríguez $^{2}$
}

\begin{abstract}
Resumen
Este artículo brinda un panorama general sobre las acciones emprendidas por el gobierno mexicano para tratar el tema de la diversidad cultural y lingüística desde la vía educativa, especialmente en el nivel básico y superior universitario. De este modo, se pretende detectar contextos, acciones y actores principales de esta problemática que influye directamente en el desarrollo de investigaciones sociolingüísticas que pueden coadyuvar a la creación de una política intercultural del lenguaje.
\end{abstract}

Palabras clave: Lengua; diversidad cultural; educación intercultural

\begin{abstract}
This article provides an overview of the actions taken by the Mexican government to address the cultural and linguistic diversity, especially at the elementary and undergraduate levels. The article aims at detecting contexts, actions and main actors involved in this problematic topic which has a direct effect on the development of sociolinguistic researches that could contribute to create a policy on intercultural language.
\end{abstract}

Keywords: Language; cultural diversity; intercultural education

Tipología: Artículo de reflexión

Recibido: 07/02/2017

Evaluado: 21/03/2017

Aceptado: 04/04/2017

Disponible en línea: 01/07/2017

Como citar este artículo: Lara, F. \& Ortega, E. (2017). La política del lenguaje y el abordaje de la diversidad cultural en el ámbito educativo mexicano. Jangwa Pana, 16(2), 267 - 281. DOI: http://dx.doi.org/10.21676/16574923.2132

1. Dr. en Lingüística. Universidad Autónoma de Chiapas. México. Correo electrónico: infaciem@hotmail.com. ORCID ID: 0000-0002-7074-2910

2. Dra. en humanidades, línea de lingüística. Universidad Autónoma de Chiapas. México. Correo electrónico: emmy_ortega@hotmail.com. ORCID ID: 0000-0003-4351-8339 


\section{Introducción}

Und na de las vías en donde la regulación del lenguaje ha tenido mayor amplitud ha sido el área educativa, pues hoy día constituye un tema central para el desarrollo tecnológico y el equilibrio económico de los Estados; en los planteamientos de diversas instituciones educativas de nivel superior y en las discusiones recientes sobre calidad y mejora de este sector se considera primordial el papel que el conocimiento y la creatividad juegan en todos los ámbitos de la estructura nacional, porque ahora se trata de la creatividad como competencia a desarrollar y del conocimiento como producto de la misma.

La escuela incide de manera significativa en la convivencia intercultural y esta última, a su vez, en las expectativas que de sus instituciones tengan los ciudadanos de un Estado, incluyendo la calidad de su enseñanza. Por ello, partiendo del hecho de que la lengua y la cultura están en el corazón mismo de los fenómenos de identidad (Warnier, 2002), el interés en el diseño de las políticas educativas ha sido el de construir un modelo de identidad unívoco o, en su defecto, tomar parte en acciones afirmativas en tanto asistencia al "problema" de la diferencia, como el caso de las universidades interculturales, instituciones de educación superior proyectadas desde el año 2004 "para promover una educación superior de calidad con pertinencia cultural y lingüística" (SEP, 2014, p. 12), las cuales, sin embargo, no han respondido a este objetivo medular debido a la poca o nula participación que los grupos culturales tienen en la formulación de sus programas educativos, así como en las estrategias comunitarias de resistencia y reivindicación étnica para afrontar la situación sociolingüística nacional (Ortega, 2011).

La paulatina tendencia a una contracción funcional entre idiomas ya ha sido bien advertida por el gobierno mexicano al mostrar

(...) una constante disminución de la población hablante de alguna lengua indígena a nivel nacional, así como una reducción de la población de cinco a 14 años que habla estas lenguas y el incremento de la población hablante en los sectores de población de mayor edad (SEP, 2014, p. 13).

Por lo que es posible afirmar que las lenguas indígenas no se transmiten a las nuevas generaciones en el seno familiar y que la escuela, idealmente, es una opción de revitalización.

Así, el tratamiento hacia la diversidad ha caracterizado un deficiente ejercicio en el sector educativo, pues la lengua, como una parte más de la cultura, ha devenido en asunto marginal a manos del gobierno federal, o al menos así se muestra en múltiples experiencias en donde el modelo bilingüe ha fracasado desde la década de 1940, y en cuya metodología pedagógica ha prevalecido el método indirecto que obliga al estudiante monolingüe a hablar solo en español, la lengua meta o L2, lo que ha provocado una creciente barrera para el aprendizaje cultural armónico y el desarrollo de una posible competencia comunicativa intercultural.

Pese a su relevancia, esta realidad todavía no es bien acogida en el ámbito de los estudios sociolingüísticos de México por el carácter multimodal que representa la política del lenguaje como objeto de estudio, pues las acciones de regulación idiomática presentan fuertes lazos con la antropología, la pedagogía e incluso con la ciencia política.

Por consiguiente, la política del lenguaje puede apreciarse como un complejo proceso sociocultural dotado de modos de interacción humana, negociación y producción mediadas por relaciones de poder (McCarty, 2004). Las decisiones sobre el lenguaje siempre han sido dependientes del contexto histórico y, por lo tanto, han devenido en acciones hegemónicas y contrahegemónicas. En el caso de México, puede decirse que la política escolar ha aplicado las nociones de orientación lingüística, actitudes hacia la lengua e ideologías lingüísticas para teorizar estos procesos (McCarty, 2011), como podrá apreciarse en los planteamientos desarrollados más adelante. 


\section{El plurilingüismo desde la perspectiva sociolingüística}

Según las estimaciones de la United Nations Educational, Scientific and Cultural Organization (UNESCO), en el mundo existen entre 6.000 y 7.000 lenguas, más de la mitad de las mismas en riesgo de desaparición (UNESCO, 2003). De acuerdo con este organismo, el plurilingüismo, entendido como "la presencia de distintos grupos lingüísticos en un mismo país donde el uso de más de una lengua para la vida cotidiana es lo habitual" (p. 13), comporta más bien la norma que la excepción en todo el mundo, y pese a esta condición de diversidad, las naciones confieren a sus idiomas la calidad de mayoritario o minoritario a partir de diversos factores que las promueven como lenguas oficiales. De este modo, el plurilingüismo acompaña, generalmente, a un multiculturalismo divergente (Bathia \& Ritchie, 2013).

Así, a la convivencia entre dos o más lenguas siempre subyace una relación jerárquica y de conflicto dado al uso extensivo de una lengua o variedad, y al consecuente desplazamiento de otra(s) lengua(s) o variantes. Se trata de una "suma de elecciones generalmente aceptadas, hechas consciente o inconscientemente, siempre que exista la posibilidad de elección permitida por la variación" (Spolsky, 2006, p. 60), lo cual constituye una política del lenguaje.

La sociolingüística ha abordado esta suma de elecciones como un fenómeno de contacto con extrema contracción funcional entre dos o más códigos en una comunidad lingüística (language community), conformada por personas que comparten la misma lengua; o de habla (speech community), integrada por un grupo de personas que no comparten la misma lengua, pero sí normas y reglas sobre los usos del lenguaje (Romaine, 1996). Tal arreglo normativo y pragmático ha sido denominado diglosia. Bajo esta perspectiva, los patrones de estratificación a los cuales los sujetos del lenguaje se exponen en el día a día explican, en gran medida, el valor social que un determinado repertorio lingüístico tiene en ciertos espacios y situaciones y que, a su vez, depende del valor social que los usuarios le asignan con sus prácticas discursivas cotidianas.

\section{La diglosia como conflicto intercultural}

Desde los postulados iniciales de la sociolingüística, la diglosia refería a un estado de lengua relativamente estable, en donde una de las variedades dialectales de dicha lengua estaba por encima de otra y a dicha variedad se le consideraba el más respetable vehículo de la literatura escrita, adquirida por medios formales, usada en el habla formal y no en situaciones de habla ordinaria; se trataba, pues, del "uso discriminado de dos variedades de la misma lengua" (Ferguson, 1959, p. 16).

Posteriormente, Gumperz (citado por Fishman, 1988) hizo notar que la diglosia existe también en sociedades que emplean dialectos o registros funcionalmente diferenciados y que pueden operar en distintos niveles lingüísticos. El autor retomaría el concepto extendiéndolo a dos sentidos en donde: 1) la diglosia podía incluir dos variedades, no solo una y 2) no era necesario que dichas variedades estuvieran emparentadas lingüísticamente; lo que hizo notar la utilización de varios códigos independientes y dentro de una única sociedad.

Fishman (1988) enfocó gran parte de sus estudios en la posible disolución de la diglosia a nivel de nación o sociedad, relacionándola con consideraciones psicológicamente pertinentes como el bilingüismo compuesto o coordinado. A pesar de las implicaciones sociales de tal diferenciación pragmática entre códigos, en sus ideas no están presentes aún las nociones de conflicto y de resistencia que han caracterizado a este fenómeno.

Así, sumado a los planteamientos de Ferguson y Fishman sobre la diglosia, emergió la noción de conflicto como perspectiva crítica. Tal postura la representan los sociolingüistas catalanes y valencianos de España, como Ninyoles (1972), y posteriormente desarrollada por los sociolingüistas occitanos en Francia.

Para Ninyoles (1972), bilingüismo y diglosia son conceptos independientes y excluyentes, en 
tanto que la diglosia es social y el bilingüismo permanece en el ámbito de lo individual. En palabras del autor: "la situación diglósica, fundada en un desequilibrio, contiene factores de inestabilidad que amenazan con quebrar la supuesta funcionalidad del sistema y que, por tanto, comportan un germen de superación" (p. 37). En esta línea, asumir que un estado de asimetría funcional es potencial en diversas prácticas discursivas trasciende las anteriores propuestas sobre diglosia, pues el uso discursivo en disputa puede pertenecer, o no, a una misma variedad de lengua. Por tanto, no es culpa del bilingüismo presente en un grupo sociocultural que existan preferencias sobre una u otra variante; sin embargo, es un factor relevante al momento de decidir sobre cuál lengua o variante elegir para cuestiones de gobernanza.

Virando la óptica hacia la situación mexicana en un sentido sociolingüístico, pocos autores han reconocido que las lenguas nacionales se encuentren en un estado diglósico en los términos planteados por la tradición lingüística americana. Por ello, y complementando las definiciones anteriores, Hamel (1988) abona a la noción de diglosia conflictiva de Ninyoles (1972) en términos de contacto intercultural, pues es posible apreciar asimetrías entre prácticas discursivas dominantes o cristalizadas en el uso del español, y prácticas discursivas dominadas, en detrimento de una lengua indígena. Lo anterior forma parte de continuum histórico capaz de disolver la diglosia hacia el desplazamiento o sustitución de la lengua indígena, aunque también puede tender hacia la resistencia, consolidación y, posiblemente, la normalización de la lengua dominada.

Hamel (1988) hizo notar que los usuarios de lenguas originarias, o indígenas, todavía lidian con el estatus de estos códigos en el ámbito jurídico, educativo y social; élubicó como un importante foco de desplazamiento a la tendencia castellanizante de las prácticas educativas, monoculturales y etnocéntricas de fondo, las cuales han ampliado su paso hacia las prácticas discursivas informales en el afán legitimador que se le concede al uso del español en ciertos eventos comunicativos.
A casi 30 años de diferencia, es menester decir que la situación en México ha tomado un rumbo inesperado, pues más allá de la visión dialectológica sobre la diversidad, los procesos políticos han obligado a tomar apertura con respecto a la situación cultural del país. Así, desde el año 2003 las lenguas originarias se reconocieron como lenguas nacionales en la Ley General de Derechos Lingüísticos de los Pueblos Indígenas, aunque todavía no hay un correlato práctico de ello. Fue a partir del mismo año que el Instituto Nacional de Lenguas Indígenas (INALI) tuvo la misión de elaborar el "Catálogo de Lenguas Indígenas Mexicanas", dispuesto en el artículo veinte de dicha ley.

El inali ha concluido que, además del español, en México se habla un total de 11 familias lingüísticas dispersadas en 68 agrupaciones, 364 variantes o formas de manifestación de las lenguas indígenas. El inventario léxico resultante establece, desde la postura del investigador, la diferencia entre variedades de lengua para los hablantes, ignorando que el estatus de la lengua estándar es asignado por la comunidad ya que "en realidad los estudios de inteligibilidad mutua no detectan parentescos lingüísticos, sino relaciones sociales, puesto que son las personas y no las variedades las que se entienden entre sí” (Romaine, 1996, p. 30).

Con lo anterior, el lugar de la diglosia como propuesta teórico-explicativa de la diferenciación jerárquica entre códigos lingüísticos es, hoy día, poco eficaz para abordar fenómenos de variación, de contacto o de desplazamiento de lenguas. Considerar únicamente la estratificación de los sistemas lingüísticos a partir de una perspectiva dialectológica dejaría de lado un fenómeno aún más relevante, esto es: la distribución de las lenguas como un continuum dinámico, pues la movilidad de los grupos sociales implica la variación de los repertorios lingüísticos, la innovación de sus formas, la reestratificación de sus usos y la consecuente reconfiguración del escenario lingüístico.

Lo anterior solo es abordable desde una sociolingüística de la movilidad (Blommaert, 
2010), para apreciar los recursos de la lengua en su contexto sociocultural en donde los sujetos del lenguaje demandan, a través de su agencia discursiva, la afirmación de las identidades etnolingüísticas como una alternativa de solución al conflicto intercultural. Dicho reconocimiento a la diferencia se sugiere a partir de la institucionalización formal del ejercicio de las lenguas nacionales.

Así, en la lógica de la diglosia conflictiva, el último efecto negativo para un sistema lingüístico es la sustitución de este por otro; sin embargo, el resquicio aún queda abierto en el caso mexicano, ya que a pesar de los procesos históricos de desplazamiento de lenguas indígenas y alfabetización en español, la resistencia del uso de estos códigos marginados ha llegado a cuestionar, incluso, la tradición monoculturalista del sector educativo, como podrá apreciarse en el siguiente apartado.

\section{La política educativa y el tratamiento a la diversidad lingüística y cultural}

La pretensión de este apartado es exponer los principales eventos coyunturales que dieron lugar a la actual visión de la educación como modelo de evolución científica, tecnológica y económica de México.

Para ello, se ofrece una breve crónica sobre la negación escolástica de las capacidades multilingües de la población mexicana a manos de su propio gobierno, así como de los cambios estructurales que sufrió el organismo encargado de ejecutar los mandatos sobre el tratamiento a la diversidad, pues a este subyace, aún hoy día, un arraigo identitario primordial para comprender la exigencia de una educación convergente y con una política intercultural del lenguaje de fondo que no excluya a los grupos etnolingüísticos del país.

\subsection{El centralismo estructural de la Secretaría de Educación Pública (SEP)}

Desde su fundación en 1921, el ideal de la SEP fue el de redimir a la posrevolucionaria y lastimada sociedad a través de la educación, posicionándose esta como un factor de movilidad social aun con varias deficiencias a nivel orgánico, programático y operante en su proyecto.

Respecto a su organización, el primer eje problemático para la eficiencia del sistema es la concentración de las decisiones en el centro. El centralismo, un rezago del pensamiento posrevolucionario unificador, es un sistema de gestión que concentra el poder en la figura personal del secretario y ejerce su autoridad en un sentido vertical, a través de mediadores cuya principal finalidad ha sido lograr una cobertura universal del sector.

Como señala Colmenares, en la formulación del modelo educativo mexicano se ha apostado a la centralización, esto es, transferir a los estados responsabilidades y pocos recursos sin perder el control (Colmenares-Páramo, 2016), como ocurre con el financiamiento de la educación básica. La SEP se reservó el control de la nómina, simulando así una descentralización que nunca existió, sobre todo en cuanto a gastos federalizados.

Se trataba de un poder, pues, administrativo, concentrado en nombramientos para puestos medios, plazas y dinero, y cuya orientación fundamental fue la de ampliar la escolarización con un trato negligente hacia los aspectos académicos (Guevara-Niebla, 1992). Tal problema estructural devino en disposiciones de carácter unitario y cerrado a la participación con respecto al diseño de los programas, chocando estos con una realidad diversa en prácticamente todo aspecto sociocultural. Puede asegurarse, por ende, que enfrentar una realidad poliédrica requiere una visión holística de la cual el sistema político mexicano careció en el ámbito de las políticas públicas enfocadas a la instrucción de su población, pues como señala Subirats (1994) los problemas pueden verse "como oportunidades de mejora, que una vez identificadas o definidas pueden poner en marcha la acción de los poderes públicos" (p. 48). 


\subsection{La unicidad curricular: negación de la complejidad}

La diversidad sociocultural es la segunda cuestión más importante abordada de modo inadecuado en el proyecto educativo mexicano. Su error programático fue - $\mathrm{y}$ sigue siendo - la unicidad del currículo, pues deviene en

(...) rasgo desconcertante en un país que tiene entre sus rasgos sustantivos, precisamente, el de la diversidad cultural [y en donde el carácter rígido y monocultural del plan de estudios] tiene también efectos inequitativos debido a que no todos los niños llegan a clases con los mismos conocimientos, habilidades, actitudes y disposiciones (Guevara-Niebla, 1992, p. 22).

Tal rigidez programática es evidente desde la década de 1930, durante el sexenio cardenista, pues a nivel de educación básica la solución al fenómeno de la complejidad lingüística y cultural se planteó en términos de una promotoría de la cultura hispanohablante a manos de profesores de origen indígena que pudieran hacerse cargo de sus propias comunidades. En ese periodo, la política educativa implicaba un giro en las relaciones entre actores locales y Estado, en cuyos objetivos fue necesario disminuir la tasa de monolingüismo en lengua indígena para alcanzar un bilingüismo que implicaba la transformación de los individuos en sujetos políticos incorporados a un nuevo orden simbólico expresado en la idea de "nación". La escuela rural se convirtió, por ende, en un escenario de negociaciones en torno a la participación de la población indígena y campesina en los asuntos de interés público, del orden de la "justicia social", tratando así de animar el concepto de nación multiétnica.

De esta suerte de pacto entre gobierno y comunidades, se creó en 1946 la Dirección General de Asuntos Indígenas, dependiente de la SEP, reorientando los internados indígenas existentes para convertirlos en centros de capacitación técnica. En 1948, estas acciones educativas conforman las políticas indigenistas del naciente Instituto Nacional Indigenista (INI), hoy la actual Comisión Nacional para el Desarrollo de los Pueblos Indígenas (CDI). De tales acciones gubernamentales pueden desprenderse dos perspectivas críticas: la intención de la mejora civilizatoria o la de una represiva dominación cultural (Tovar, 2004).

En esa línea, la década de 1940 significó una reorganización de casi todos los sectores administrativos del país, reflejándose la reforzada tendencia a la unificación nacional en la redacción de la Ley Orgánica de Educación, reglamentaria del artículo tercero constitucional, que delineó el camino homogeneizador de los planes y programas educativos de todo el país. En este nuevo y confuso escenario, el Estado mexicano muestra el pleno desinterés ante la composición plurilingüe de su entorno al delegar el registro de sus múltiples lenguas al Instituto Lingüístico de Verano (ILV), institución que aparece en el marco de un acuerdo para realizar investigación antropológica, además de una encubierta - pero bien conocida - "labor de evangelización y penetración ideológicopolítica" (Tovar, 2004, p. 271).

Con este panorama, el Instituto Nacional Indigenista creó en 1963 un programa de reclutamiento y formación de promotores culturales, el mismo que para 1970 formaría la planta docente de la SEP y, paulatinamente, el 1lamado Subsistema de Educación Indígena. Este Servicio Nacional de Promotores Culturales y Maestros Bilingües requería de sus miembros una obligada identidad originaria, a fin de disminuir la brecha comunicativa entre lo indígena y lo occidental para, finalmente, integrar al indio a la sociedad nacional a través de la escuela (Rebolledo, 2005).

Ante esta declarada labor de aculturación, de 1962 a 1970, emergió el discurso indigenista que establecía la relación necesaria entre las prácticas pedagógicas y los docentes originarios; surgió también un discurso de la reivindicación cultural e histórica a manos de los profesorespromotores pues, argumentaban, se trató de un replanteamiento de la identidad indígena a partir de la modernidad (Rebolledo, 2005). Este fue un síntoma de la cambiante subjetividad social que reclamaba el desvanecimiento de la ficticia 
unidad nacional a toda costa; se trató de un momento de efervescencia política que provocó un giro en las concepciones indigenistas y, como notó Carlos Monsiváis, la ensoñación tradicional de lo mexicano se desvaneció, presentándose lo multicultural bajo un presionado contexto de miseria, pobreza, marginalidad de los grupos indígenas, corrientes migratorias, así como del crecimiento de la conciencia femenina (SánchezRebolledo, 1992).

Fue hasta la campaña presidencial de Miguel de la Madrid - a principios de la década de 1980 que se reconoció la existencia, o al menos la idea, de un México plural otrora marcado por la homogeneidad de una lengua, una religión y una versión de la historia aportada por la Revolución Mexicana. Sin embargo, su intención descentralizadora recién propuesta no tuvo éxito pues, en su discurso de toma de posesión, externó su voluntad de transferir a los gobiernos locales los correspondientes recursos y servicios de educación preescolar, primaria, secundaria y normal, pero dicha descentralización de la educación básica provocó la resistencia del sindicato de maestros hasta declinar (Tovar, 2004).

Ante esta oleada de eventos, el gobierno priista emprendió acciones de parcial armonía entre este y los sectores originarios reconociendo la demanda de una educación bilingüe de iniciativa profesional; así, surge en 1981 la Dirección General de Educación Indígena (DGEI), dependiente de la subsecretaría de Educación Básica de la SEP. Para 1982, tanto el INI como la DGEI se alinearon a las metas de la SEP: "eliminar el analfabetismo en zonas indígenas a través de la castellanización y por medio de la escuela primaria bilingüe" (Tovar, 2004, p. 274).

La separación del Sistema de Educación Indígena de la estructura del Sistema Educativo Nacional no solo fue administrativa, sino también pedagógica y política. Oficializado así el sesgo a la diferencia, en la aún diversa sociedad comenzó a cristalizarse la indolencia hacia los temas sobre educación, extendiéndose la creencia de que cualquier tipo de instrucción es útil y, por tanto, la verificación sobre lo acontecido en los centros educativos quedó fuera del debate nacional por mucho tiempo. Tal apatía es una continuación de la cultura corporativa posrevolucionaria, la misma que ha aislado al sector educativo de la sociedad y de su participación en la gestión educativa de México, pues no existe algún tipo de evaluación global y regular que pueda presentarse públicamente como reflejo de la administración de los recursos que la sociedad invierte en educación (Guevara-Niebla, 1992).

\subsection{El alineamiento de las fuerzas magisteriales}

El tema de la apatía hacia la evaluación de la calidad educativa nos lleva a considerar necesariamente la labor docente. El magisterio, reflejo también de la cultura corporativista del sistema político mexicano, ponderóla idea de que la responsabilidad máxima en la educación mexicana descansa sobre sus maestros, organizados en uno de los sindicatos más poderosos de América Latina, el Sindicato Nacional de Trabajadores de la Educación (SNTE).

A partir de la década de 1960, con la puesta en práctica de la educación bilingüe a manos de los profesores indígenas, ocurrió un reordenamiento político del sector magisterial. Primero, se trató de un posicionamiento de su identidad en el entramado social, pues tanto en escenarios urbanos como rurales, los profesores ladinos y mestizos discriminaban a los indios que intentaban ladinizarse al olvidar su identidad originaria por medio de la profesionalización, así como a los que anhelaban distanciarse económicamente del resto de la población indígena como límite simbólico de las relaciones interétnicas (Rebolledo, 2005).

La crítica hacia la participación gremial del sector indígena - aún en estos tiempos - señala la retórica de una revitalización lingüística y cultural opacada por una participación activa en asuntos meramente administrativos; fórmula que se ha repetido con el resto de los maestros de origen "mestizo". Tal dinámica dio origen a un sindicato disidente en 1977, cuando olas crecientes de maestros levantaron sus reivindicaciones $\mathrm{y}$ pidieron la democratización de su gremio, tras numerosas movilizaciones surgió la Coordinadora 
Nacional de Trabajadores de la Educación (CNTE) (Guevara-Niebla, 1992).

La importancia estructural del SNTE, en este análisis, descansa en la ya mencionada imposibilidad de intervención de sus afiliados, práctica democrática negada que limita cualquier reconocimiento a la diferencia de opinión, iniciativa y/o modificación a la configuración de los programas y sistemas de enseñanza del modelo educativo mexicano: un reflejo más del desconocimiento a lo diverso que influye, de modo crucial, en los contenidos impartidos al México "homogéneo", pues a través de la selección de estos se fortalece la construcción de la unidad en la diferencia $y$, entonces, la competencia intercultural.

La consecuencia lógica de la supremacía de la burocracia en el SNTE, y de la visión unitaria en los contenidos y en la dinámica docente, deriva en pensamientos cuasifundamentalistas que colocan a una de las muchas identidades por encima de las demás. Nuevamente, Monsiváis (citado por Sánchez-Rebolledo, 1992) es tajante al respecto:

El "México Unívoco" obstaculiza cómo puede el desarrollo de la diversidad. La libertad de creencias se extiende, y son millones los que se acercan a la religión de otras maneras. Y, entre la explosión de prácticas culturales, se esparce el espíritu de aceptación o de comprensión de lo diverso, de lo otro, que modifica a fondo la imagen totémica monopólica, absolutista de la vida nacional (p. 49).

En todo lo anterior, la diversidad cultural parece nuevamente un asunto de baja relevancia pero, en los últimos años, ha debido ser tópico de importancia internacional dadas las crecientes migraciones e intercambios socioculturales que "afectan" la clásica idea de la educación unitaria $\mathrm{y}$, por tanto, de las poblaciones homogéneas de jóvenes con intereses y metas similares.

\subsection{El modelo de educación superior}

Según el Centro Interuniversitario de Desarrollo (CINDA, 1993), el arquetipo de universidad mexicana nació en Hispanoamérica, durante el siglo XVI, bajo el modelo de las universidades de Ávila y Salamanca, cuya metodología expositiva tenía como finalidad capacitar a sus estudiantes para el servicio de la Iglesia y del Estado.

No obstante, las universidades nacionales tomaron un carácter más funcional, estatal y laico en virtud de las ideas liberales posindependentistas, pues en 1824 se adoptó el sistema federal que dotaba de soberanía a los Estados para tutorar la enseñanza superior bajo el modelo educativo de los institutos científicos o colegios civiles y con el firme propósito de laicizar los conocimientos (Piñera-Ramírez, 2004).

Aún con ello, el racionalismo y el desarrollo de las ciencias naturales orientaron el desarrollo de la docencia conservando su colonial esquema expositivo y memorístico (CINDA, 1993), un gran freno para el pensamiento crítico el cual debe formar parte de una educación adecuada para la vida en una democracia pluralista y de carácter multicultural.

Durante el siglo XX, los movimientos sociales y experiencias como la de la Universidad de Córdoba, en 1918, y los procesos de cambio iniciados a finales de 1960, generaron modelos universitarios alternativos promovidos en todos los países por los movimientos de reforma y que hacen de la docencia una práctica más integral, fomentando en el alumno su desarrollo investigativo y vinculado a la realidad sociocultural.

Esta reciente visión humanista situó a la educación superior como una institución de bases éticas incluso en la modalidad de institutos y colegios, situación que se prolongó hasta mediados del siglo XX al convertirse, la mayoría de ellos, en universidades públicas estatales.

El México agrícola transitó a lo urbano e industrial tras la Segunda Guerra Mundial y ello alineó a la educación universitaria con las nuevas condiciones del país, tendientes todas hacia una política general de Estado benefactor, como producto del proceso de formación del 
Estado posindependiente y, posteriormente, de la consolidación y transformación del Estado nacido de la Revolución de 1910.

Ya en 1950, ante la creciente expansión de las universidades estatales, la Asociación Nacional de Universidades e Instituciones de Educación Superior (ANUIES) surgió para mediar la relación de estas con las instancias educativas federales. Años después, en el marco del creciente fomento al pensamiento crítico y tras la herida provocada por el movimiento estudiantil de 1968, el régimen del presidente Luis Echeverría (1970-1976) facilitó amplios programas de asistencia para las instituciones de educación superior del país, como efecto de un Estado benefactor ya instaurado (Piñera-Ramírez, 2004).

Así fue como se apoyó a las universidades de los Estados de la República en aras de desconcentrar la población estudiantil y se propició la creación de más, y a través de las acciones de la SEP, la ANUIES y el CONACYT (Consejo Nacional de Ciencia y Tecnología), se consolidó en la etapa de 1970-1982 lo que hoy puede denominarse Sistema Nacional de Educación Superior de México. Lo anterior dio al concepto de universidad un nuevo sentido de retribución ciudadana en tanto institución mediadora, reproductora y creadora de la cultura a través de la investigación y creación cultural, la docencia y la extensión, y cuyo quehacer y resultados se encuentran al servicio del hombre y de la sociedad, por lo que debe responder y rendir cuentas a la misma (CINDA, 1993).

\section{La diversidad como tema de agenda pública}

El tema de la presencia multicultural en las Instituciones de Educación Superior (IES) demanda un análisis que rebasa la subestimación estadística y el mito de que a las minorías corresponden menores atenciones; la cuestión representa cualidad y no cantidad, por tanto demanda pertinencia más no segregación.

Del discurso público de la juventud mexicana universitaria, emana la idea de que el derecho a la diferencia de pensamiento y acción no implica atomización social; con ello, es posible afirmar que las actuales demandas de reivindicación de los múltiples colectivos culturales han ganado sitio como asunto público a resolver, y entonces las vías de resolución dependerán del número de afectados por el problema, las medidas de solución que se logren, los intereses afectados y el nivel y tipo de organización que se siga (Subirats, 1994).

En el entendido de que el país es un vértigo noticioso toda vez que se aborda el tema de la educación y del respeto a la libertad de expresión, el tratamiento a la diversidad exige una reconsideración en sus planteamientos a partir de una muestra antropológica y etnográfica de los contactos multiculturales, como inicio de evaluación y ubicación de los errores cualitativos presentes también en las IES no interculturales en la oficialidad.

Por tanto, la perspectiva del mirar "de abajo hacia arriba", usada recientemente en la evaluación de políticas públicas, permite aclarar en qué medida el programa oficial, con su conjunto de objetivos, normas procedimentales, recursos, etc., ha influenciado efectivamente los resultados finales de la política en cuestión, pues este modelo de tipo bottom up permite encontrar las limitaciones básicas en que se mueven los actores implicados para lograr una administración con plena libertad de acción (Subirats, 1994).

Al segmentar las IES en interculturales $y$ "convencionales", se ha emprendido una política del lenguaje enfocada a los entornos indígenas, considerando que la variable regional predomina sobre la migración y el contacto sociolingüístico permanente.

Debido a que aún no se cuenta con una metodología cualitativa adecuada para establecer el éxito o fracaso de una política pública, es necesaria una perspectiva multidisciplinaria que dé cuenta de la situación sociolingüística con relación al prestigio y funcionalidad idiomática al interior de una IES, pues distinguir entre las prácticas legitimadas por la población general y las definiciones legalizadas por el Estado mexicano ayuda a comprender la actual política del lenguaje en México. 


\subsection{Las IES interculturales}

Desde el proyecto educativo 1995-2000 de la SEP, y durante el gobierno de Vicente Fox (20002006), el sistema educativo ha promovido la instauración de la 'educación intercultural' en el subsistema educativo indígena, a fin de encauzar la forma y contenido de los planes de estudio hacia la difusión y conservación de las lenguas y los ambientes de la población indígena del país. Tal propuesta vio sus orígenes cuando la política indigenista en México decidió pasar de la 'educación bicultural bilingüe' a la 'intercultural', cuya premisa consistió en la no imposición de un sistema educativo hispanohablante sobre la cosmovisión de los diversos grupos étnicos.

Para ello, a través de la Coordinación General de Educación Intercultural y Bilingüe (CGEIB), de la Secretaría de Educación Pública, se anunció en 2004 la creación de diez universidades interculturales en zonas con importante presencia demográfica indígena para "formar profesionales e intelectuales comprometidos con el desarrollo de sus pueblos y regiones" (Sandoval, 2004, p. 50), buscando con esto que sus egresados permanezcan o regresen a sus culturas y lugares de origen.

Actualmente, México cuenta con once universidades descentralizadas con este enfoque (SEP, 2016) y en la mayoría de estas se observan fuertes discordancias en su funcionamiento, pues su política educativa no armoniza aún con el derecho internacional en cuanto a libre determinación y a la necesidad de contar con el consentimiento previo, libre e informado de las comunidades en la elaboración de políticas y programas dirigidos a pueblos indígenas.

Este último aspecto sobre la posible autonomía ha sido fuertemente criticado por los usuarios del enfoque intercultural, pues la eficacia del mismo se pone en duda al pretender la vinculación del estudiante y su comunidad al término de su formación académica, ya que resulta contradictoria la inclusión de un individuo, formado en el marco de cierta especificidad cultural, a un entorno que no le concede la posibilidad de opinión y participación para las que, se supone, fue instruido (Ortega, 2011). Es en esta dimensión humanística que los reclamos sobre derechos e identidad apuntan hacia la necesidad de una legitimación jurídica de los grupos culturales minoritarios.

Para la CGEIB, la interculturalidad se inscribe en el marco de una interacción que asume la diversidad como riqueza, fundada en la otredad como recurso básico de la democracia cultural y la cual se vale del diálogo y el respeto para lograr una nueva comprensión de la universalidad cultural en ámbitos tanto locales como globales (SEP-CGEIB, 2007).

Sin embargo, la misma naturaleza de la institución llamada intercultural establece una diferenciación política, económica y cultural frente al aparato hegemónico estatal, desatando esto discursos disímiles en torno a la posible integración del estudiante universitario intercultural en la economía del país.

Esta nueva política intercultural contiene matices tenues de separatismo, pues en el marco de una nación concebida como pluricultural, en el artículo segundo constitucional se indica que dichas comunidades "conservan sus propias instituciones sociales, económicas, culturales y políticas, o parte de ellas" (Const., 2017, art. 2).

A tal organización conservadora subyace una noción de etnicidad como principio organizador ya que, según el artículo segundo, "la conciencia de su identidad indígena deberá ser criterio fundamental para determinar a quienes se aplican las disposiciones sobre pueblos indígenas" (Const., 2017, art. 2) pero, al mismo tiempo, deviene una diferenciación categorial respecto al estatus de ciudadano con respecto al de indígena:

(...) mientras el ciudadano es aquel que pertenece a una comunidad política, adquiriendo derechos fundamentales y obligaciones que le hacen mantener la condición de ciudadanía e involucrando en ello un sentimiento de pertenencia hacia tal comunidad, el indígena parece carecer de tal arraigo hacia la sociedad política - o Estado nación-, estableciéndose su pertenencia a una colectividad de organización independiente y 
ajena de aquella dotada de oficialidad, otorgando así al término 'indígena' una distinción derivada de la de ciudadano (Ortega, 2011, p. 41 y 42).

Esta falta de definición sobre el estatus jurídico del ciudadano indígena repercute en la formulación de una política intercultural, pues a partir de la distinción de dos grupos al interior de un Estado es necesario un tratamiento plural que posibilite el intercambio y el reconocimiento. Así, la interculturalidad no se propone una convivencia armónica entre la cultura hispanohablante y alguna originaria, pues esta se orienta hacia el mismo sector indígena, retroalimentándose así la conservación de las instituciones no oficiales aunque antiguas y, por tanto, la diferencia jurídica entre ciudadanos mexicanos y ciudadanos mexicanos indígenas.

\subsection{La diversidad cultural desde una incipiente política del lenguaje}

En general, aún no existe un acuerdo estable sobre el estatus teórico de la política del lenguaje en el campo de estudio sociolingüístico mexicano pues, aunque notable, el tema ha sido relegado al ámbito de la documentación a manos del INALI y el análisis formal de los sistemas lingüísticos como parte de una estrategia general de planificación; dichos trabajos han apostado por el registro de las varias lenguas originarias del país, como un intento por salvaguardar el legado cultural que — para la academia - representan estas realidades vivas. La mayoría de los enfoques existentes establecen dos grandes áreas de análisis:

1. La política del lenguaje "externa", que se refiere al papel de cada lengua, es decir, sus usos y funciones en un contexto multilingüe.

2. La política del lenguaje "interna", que analiza la intervención sobre las normas gramaticales, la codificación, estandarización, la elaboración de alfabetos y vocabularios (Hamel, 1993, p. 8).

La prioridad en México ha sido el área de la política del lenguaje interna y, con ello, se ha menospreciado al modelo de política externa en tanto este implica a la sociolingüística, pragmática y análisis del discurso - entre otros enfoques teórico-metodológicos - que analizan la dinámica de los intercambios comunicativos en un contexto cada vez más global y, en el caso de los Estados, más multicultural.

\section{Discusión}

En el caso de México, la población contenida en el Estado desde antes de su configuración como unidad política ha resurgido a los ojos y oídos de lo mayoritario para modificar la modalidad de marginación por una de convivencia e inclusión no asimilativa.

De este modo, la composición pluricultural de México constituye un parteaguas importante para definir las acciones dedicadas a reivindicar la identidad cultural y a promoverla como recurso de desarrollo intelectual y de potencial calidad de vida para los miembros de cualquier comunidad.

La educación mexicana ha procurado iniciar este camino de reconocimiento a partir de la propuesta de la interculturalidad como plataforma humanista que, si bien pondera el desarrollo integral de la comunidad estudiantil vista como comunidad cultural ante las exigencias del entorno, aún requiere permear más profundo en las venas de la enseñanza monocultural e hispanohablante que aún prevalece en el moderno concepto de universidad mexicana.

Por ello, para una disciplina como la lingüística que se dedica en varias de sus líneas de especialización al tema del análisis y la descripción de lenguas, la consideración de la diversidad idiomática comienza a ser asunto de agenda política y educativa, pues los sujetos del lenguaje también son aquellos que conforman la matrícula escolar en tanto ciudadanía heterogénea, bilingüe, flexible y capaz de adaptarse a las dinámicas sociolingüísticas que exige la educación mexicana actual.

La política del lenguaje en México, en tanto propuesta disciplinaria, aún se encuentra supeditada a un básico entender de las acciones de 
resistencia cultural vistas como acciones positivas de planificación y revitalización lingüística. La consecuencia lógica de esta visión tiene dos vertientes:

1) Por un lado, se sigue la tradición de normalizar y estandarizar determinadas variantes lingüísticas sin un seguimiento etnográfico de las prácticas comunicativas y discursivas con y por sus usuarios, lo que dio como resultado caótico y descontrolado una serie de programas, materiales de enseñanza y estrategias de difusión no reconocidas, ni mucho menos reproducidas, por los hablantes en cuestión.

2) Se asume, en segundo término, que la revitalización es la alternativa a la muerte lingüística, fenómeno que rompe con todos los postulados sobre el dinamismo y adaptación que caracteriza a los procesos culturales. La lengua es parte de los cambios socioculturales y lo es, por ende, la reconfiguración de los sistemas lingüísticos que, dicho sea de paso, no mueren, así como tampoco mueren las identidades de quienes portan estos sistemas lingüísticos.

De este modo, la lógica actual de la investigación lingüística es origen y destino de las prácticas educativas que también se ven permeadas por este entendimiento acotado y estático sobre lo diverso, sobre el bilingüismo como problema en tanto se trate de lenguas originarias, indígenas, autóctonas, vernaculares, o como quiera llamárseles.

También la educación hispanohablante entraña procesos de creación, contacto cultural, reconfiguración y recreación de los códigos que hoy día conforman lo que denominamos español; por consiguiente, ¿no sería enriquecedor contemplar los procesos que han abonado a la consolidación del español como una de las lenguas nacionales? Es decir, ¿no sería revelador apreciar que el español y las lenguas indígenas están cada vez más emparentados a todo nivel de análisis lingüístico?

La política del lenguaje en México se ha reducido a una limitada noción de lo político como medidas explícitas e implementadas por instituciones autorizadas, ignorándose que "las medidas de mayores consecuencias suelen ser, por lo general, aquellas que orientan un conjunto de fuerzas sociales y que funcionan muchas veces a espaldas de los afectados" (Hamel, 1993, p. 18).

Spolsky (2006) sistematizó esta dinámica del poder social de las lenguas y sus usuarios dividiendo a la política del lenguaje en tres componentes distintivos para comprender su funcionamiento. Al primero lo nombró 'lenguaje en la práctica', el cual "consiste en el comportamiento observable y las elecciones hechas por miembros de la comunidad lingüística" (Spolsky, 2006, p. 61), que se vale de lo que Hymes en 1974 etiquetó como etnografía de la comunicación. Al segundo lo nombró 'creencias sobre el lenguaje' y al tercero 'administración del lenguaje'. Sin ahondar por el momento sobre tal propuesta teórica, cabe una reflexión final sobre el tratamiento a la diversidad en México, y es que la administración del lenguaje oficial no ha considerado, a causa de las predominantes creencias sobre el lenguaje, la implementación de un proyecto nacional para registrar la naturaleza del lenguaje en la práctica de las muchas comunidades de habla existentes en nuestro país. Emprender tal labor arrojaría una realidad temible para el conservadurismo posrevolucionario, y es que, seguramente, no contamos tan solo con 11 familias lingüísticas dispersadas en 68 agrupaciones, 364 variantes o formas de manifestación de las lenguas indígenas, sino con múltiples fluctuaciones de variantes, usos y emergencias pragmáticas no reconocidas.

\section{Conclusiones}

En sus labores de aproximación a la diversidad, el modelo educativo dominante en México ha sido el de la educación no inter, sino multicultural debido a que esta ha desarrollado -como consecuencia del pensamiento posrevolucionario unificador- una acción socioeducativa de base ideológica centrada en la diferencia. 
La desmitificación sobre lo proclamado por las autoridades mexicanas como educación intercultural puede apreciarse en los hechos mismos toda vez que, en un marco social influido por el principio de la interculturalidad, se llevarían a cabo acciones socioeducativas inspiradas en una plataforma ética interesada en la inequidad, en la discriminación racial y lingüística y, por tanto, esta hipotética sociedad educada para la diferencia se entregaría en un afán por desdibujar aquello que es divergente con los principios interculturales: una dinámica política que en México aún no existe.

Por consiguiente, la diversidad cultural y lingüística de México es una evidencia empírica que sirve de herramienta para repensar y diseñar un nuevo y necesario proyecto educativo, pues la enseñanza no será intercultural sólo por contener a una multiplicidad de usuarios bilingües, sino porque se tome la decisión de concebirla como un derecho a ejercer la diversidad. La reforma política propuesta conlleva, de fondo, una mayor responsabilidad para el Instituto Nacional de Lenguas Indígenas de México (INALI) al cual, indirectamente, se le solicita la elaboración de material pedagógico pertinente para cada comunidad lingüística, labor que actualmente se desarrolla bajo la perspectiva de la documentación, adoleciendo por ello de un previo trabajo etnográfico para recuperar los saberes culturales tan demandados en prácticamente todas las comunidades de la República mexicana.

Esta necesidad de un adecuado diseño curricular fortalecido por materiales cultural y lingüísticamente pertinentes se perfila no sólo para el sector indígena, sino para todos los estudiantes mexicanos. Tal reforma nacional constituiría una política del lenguaje explícita en cuya estructura organizacional fungiría la participación de las autoridades tradicionales legitimadas, entonces, por la creación de una institución dedicada a gestionar, de modo independiente, los recursos dedicados al desarrollo de las comunidades indígenas, así como una apropiada vinculación con el ámbito económico.
En principio, parecería que la propuesta de este artículo tiende a una suerte de política indigenista de segunda generación con marcados tintes multiculturalistas; sin embargo, un multilingüismo pluralista supone la apropiación de los conocimientos comunitarios en el seno mismo de las prácticas tradicionales y, también, una concientización y apropiación lingüística regional en los espacios predominantemente hispanohablantes: una nueva política del lenguaje que implica la enseñanza de la lengua regional como acto de comunicación intercultural, desde el seno mismo del conflicto intercultural actual.

\section{Agradecimientos}

A la Maestría en Estudios Culturales (MEC), por promover a través de la línea de investigación 'Estudios socioculturales del lenguaje' la reflexión constante en torno a las relaciones interculturales mediadas por los usos lingüísticos. Al Consejo Nacional de Ciencia y Tecnología de México (CONACyT) por financiar el desarrollo de una investigación cuyos planteamientos iniciales se ofrecen en este escrito. A todos ellos, gracias.

\section{Referencias bibliográficas}

Bathia, T. K. \& Ritchie, W. (2013). The handbook of bilingualism and multilingualism. Oxford: Wiley-Blacwell.

Centro Interuniversitario de Desarrollo (CINDA) (1993). Acreditación universitaria en América Latina. Antecedentes y experiencias. México: Asociación Nacional de Universidades e Instituciones de Educación Superior (ANUIES) Organización Universitaria Interamericana (OUI).

Colmenares-Páramo, D. (2016). Centralismo y financiamiento educativo. El financiero. Recuperado de http://www.elfinanciero.com. $\mathrm{mx} /$ opinion/centralismo-y-financiamientoeducativo.html 
Constitución Política de los Estados Unidos Mexicanos [Const.]. (5 de febrero de 1917). [Reformada el 24 de febrero de 2017]. México: Diario Oficial de la Federación. Recuperado de http://www.diputados.gob.mx/LeyesBiblio/ref/ cpeum.htm

Ferguson, C.A. (1959). Diglosia. En P. Garvin \& Y. Lastra. (1984) (Eds.), Antología de etnolingüística y sociolingüistica (pp. 247-265). México: UNAM.

Fishman, J. A. (1988). Sociología del lenguaje. Madrid: Ediciones Cátedra.

Guevara-Niebla, G. (1992). El malestar educativo. Nexos, 170, 21-36.

Hamel, R. E. (1988). La política del lenguaje y el conflicto interétnico. Problemas de investigación sociolingüística. En E. P. Orlandi. (Ed.), Política lingüistica na América Latina (pp. 41-73). Campinas: Pontes.

Hamel, R. E. (1993). Políticas y planificación del lenguaje: una introducción. Iztapalapa, 29, 5 -39.

McCarty, T. L. (2004). Dangerous difference: a critical-historical analysis of language education policies in the United States. En J. W. Tollefson y A. B. M. Tsui (Eds.), Medium of instruction policies: Which agenda? Whose agenda? (pp. 7193). Mabwah, NJ: Lawrence Erlbaum.

McCarty, T. L. (2011). Ethnography and language policy. New York: Routledge.

Ninyoles, R. (1972). Idioma y poder social. Madrid: Tecnos.

Ortega, E. (2011). Fortalecimiento etnolingüístico en México. La estrategia intercultural desde el discurso universitario mazahua, México: Editorial Académica Española.

Piñera-Ramírez，D. (2004). Las universidades públicas estatales y el estado benefactor en
México, IV Congreso Nacional La universidad como objeto de investigación. Conferencia llevada a cabo en la Universidad de Tucumán, Argentina.

Rebolledo, N. (2005). Educación y etnicidad. En J. Tirzo-Gómez. (coord.), Educación en interculturalidad. Miradas a la diversidad (pp. 52-75). México: UPN.

Romaine, S. (1996). El lenguaje en la sociedad. Una introducción a la sociolingüística. Barcelona: Ariel lingüística.

Sánchez-Rebolledo, A. (1992). México 1992: ¿Idénticos o diversos? Una entrevista a Carlos Monsiváis. Nexos, 178, 49-52.

Sandoval, E. (2004). Universidades interculturales. Modelo del indigenismo en la globalización. En S. Corona-Berkin y R. Barriga-Villanueva (Eds.), En Educación indígena. En tornoa la interculturalidad (pp. 42-55). México: Universidad de Guadalajara - Universidad Autónoma Metropolitana.

Secretaría de Educación Pública. (2014). Programa especial de educación intercultural 2014 - 2018. México: Diario Oficial de la Federación. Recuperado de http://www.gob. $\mathrm{mx} / \mathrm{sep} /$ documentos/programa-especial-deeducacion-intercultural-2014-2018.

SEP-CGEIB (2007). Políticas y Fundamentos de la Educación Intercultural Bilingüe en México. México: SEP.

Spolsky, B. (2006). Prolegómeno a una teoría de políticas del lenguaje y ordenamiento lingüístico para el siglo XXI. En R. Terborg \& L. García (Eds.), Los retos de la planificación del lenguaje en el siglo XXI (pp. 59-76). México: Centro de Enseñanza de Lenguas Extranjeras, UNAM.

Subirats, J. (1994). Análisis de políticas públicas y eficacia de la administración. Madrid: MAP. 
Tovar, M. P. (2004). Estudio sobre la educación para la población rural en México. En UNESCO (Ed.) Seminario Educación para la población rural (EPR) en América Latina: alimentación y educación para todos (pp. 265-275). Santiago de Chile: Organización de las Naciones Unidas para la agricultura y la alimentación.
UNESCO (2003). La educación en un mundo plurilingüe. París: United Nations Educational, Scientific and Cultural Organization (UNESCO).

Warnier, J.P. (2002). La mundialización de la cultura. Barcelona: Gedisa. 